\title{
Agronegocio, deforestación y disputas en torno al Ordenamiento Territorial de Bosques Nativos de la provincia de Córdoba (Argentina)
}

Agribusiness, Deforestation and Disputes around the Native Forest Land Management of the Province of Córdoba (Argentina)

Agronegócio, deflorestação e disputas em torno ao Ordenamento Territorial de Bosques Nativos da província de Córdoba (Argentina)

Esteban Salizzi*

Recibido: 7 de junio de 2019

Aprobado: 15 de abril de 2020

Doi: https://doi.org/10.12804/revistas.urosario.edu.co/territorios/a.7982

\section{Para citar este artículo:}

Salizzi, E. (2020). Agronegocio, deforestación y disputas en torno al Ordenamiento Territorial de Bosques Nativos de la provincia de Córdoba (Argentina). Territorios, (43), 1-28. https://doi.org/10.12804/revistas. urosario.edu.co/territorios/a.7982

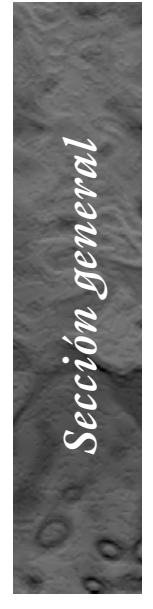


Palabras clave

Agronegocio; Córdoba; deforestación; frontera agraria moderna;

Ordenamiento

Territorial de Bosques Nativos.

Keywords

Agrobusiness; Córdoba; deforestation; modern agrarian frontier; Native Forest Land Management.

Palavras-chave Agronegócio; Córdoba; deflorestação; fronteira agrária moderna;

Ordenamento

Territorial de Bosques Nativos.

territarias 43
RESUMEN

El objetivo del artículo consiste en realizar un aporte al estudio de las consecuencias ambientales generadas por la expansión territorial del modelo productivo de los agronegocios en Argentina, enfocando la atención en el proceso de deforestación impulsado a través del avance de la frontera agraria moderna sobre los departamentos del norte de la provincia de Córdoba (Río Seco, Sobremonte y Tulumba). Se identifican y analizan tres aristas de la problemática indicada: i) el proceso de deforestación propiamente dicho, donde se tienen en consideración las transformaciones generadas por la expansión del modelo productivo de los agronegocios en los inicios de la década de 2000; ii) la lucha de intereses que puso de manifiesto la discusión y sanción de la Ley Provincial 9814 (de Ordenamiento Territorial de Bosques Nativos) en el año 2010; y iii) sus alcances y perspectivas en relación con la situación actual de los bosques nativos del norte provincial.

\section{ABSTRACT}

The objective of the article is to make a contribution to the study of the environmental consequences generated by the territorial expansion of the agribusiness production model in Argentina, focusing the attention on the deforestation process promoted through the advance of the modern agrarian frontier over the departments of the north of the province of Córdoba (Río Seco, Sobremonte and Tulumba). Three aspects of the indicated problem are identified and analyzed: i) the actual deforestation process, which takes into consideration the transformations driven by the expansion of the agroindustry production model in the early 2000 ; ii) the fight of the interests that made manifest the discussion and the sanction of the Provincial Law 9814 (of Land Management of Native Forests) in the year 2010; and iii) its scope and perspectives in relation to the current situation of the native forests of the north of the province.

\section{RESUMO}

O objetivo do artigo consiste em realizar um aporte ao estudo das consequências ambientais geradas pela expansão territorial do modelo produtivo dos agronegócios na Argentina, focando a atenção no processo de deflorestação impulsionado através do avanço da fronteira agrária moderna sobre os departamentos do norte da província de Córdoba (Rio Seco, Sobremonte e Tulumba). Se identificam e analisam três aristas da problemática indicada: i) o processo de deflorestação propriamente dito, onde se têm em consideração as transformações geradas pela expansão do modelo produtivo dos agronegócios no começo da década de 2000; ii) a luta de interesses que estabeleceu a discussão e sanção da Lei Provincial 9814 (de Ordenamento Territorial de Bosques Nativos) no ano 2010; e iii) seus alcances e perspectivas em relação à situação atual dos bosques nativos do norte provincial. 


\section{Introducción}

El presente artículo busca realizar una contribución al estudio de las consecuencias ambientales generadas hacia finales del siglo $\mathrm{xx}$ por la expansión territorial del modelo productivo de los agronegocios sobre zonas del centro y norte de Argentina, consideradas marginales en términos agroproductivos y caracterizadas por una gran fragilidad ecológica. Con esta finalidad analiza el proceso de deforestación impulsado a través de la difusión en gran escala del cultivo de commodities agrícolas (principalmente soja), tomando como referencia los departamentos Río Seco, Sobremonte y Tulumba, ubicados al norte de la provincia de Córdoba. Conjuntamente, releva la discusión y puesta en práctica de la Ley Provincial 9814 (de Ordenamiento Territorial de Bosques Nativos) hacia finales de la década de 2000, que regula desde entonces los bosques nativos provinciales, y describe sus principales alcances y perspectivas en el norte cordobés.

El abordaje propuesto se enmarca en una aproximación teórico-metodológica de más amplio alcance, centrada en el estudio de las características espaciales adoptadas por el avance de la frontera agraria moderna en áreas de penetración agroindustrial reciente. En ella no solo se considera el proceso de reestructuración productiva en curso, sino también los efectos concurrentes, como la difusión de nuevos sistemas técnicos y el incremento de la conflictividad social (Salizzi, 2017). En términos generales, la frontera agraria moderna es pensada como el área donde se encuentran proyectos antagónicos de ocupación y organización productiva del espacio. Allí, la introducción de cultivos intensivos en capital y tecnología conduce a un proceso de redefinición general de los ecosistemas y las relaciones sociales de producción, cuyas principales consecuencias en Argentina son el desmonte de extensas áreas de bosque nativo y el desplazamiento de los pequeños productores locales (Manuel-Navarrete et al., 2005; Gómez Lende \& Velázquez, 2018).

Los departamentos del norte cordobés (Río Seco, Sobremonte y Tulumba) asisten en las últimas décadas a una radical transformación de su estructura productiva, que ha impulsado profundas alteraciones ambientales. Se trata, fundamentalmente, de la conversión de extensas áreas de bosques y pastizales en campos de forrajes adaptados a condiciones de estrés climático (megatérmicos) y cultivos anuales (soja y maíz). Así mismo, se observan efectos subyacentes a estas dinámicas, como contaminación por uso de agroquímicos, sobrepastoreo por arrinconamiento del ganado, incendios rurales y crecientes restricciones en el acceso a fuentes de agua de calidad (Salizzi, 2017).

Las problemáticas ambientales anteriormente descritas pocas veces han tomado visibilidad a nivel local a través de conflictos abiertos entre sectores de la sociedad. Una de las escasas expresiones de territarias 43 
${ }^{1}$ El artículo 60 del Decreto Nacional 91/09, a través del cual se reglamentó la Ley 26331, establece que el OTBN de cada jurisdicción debe actualizarse cada cinco años, contando a partir de su sanción.

\section{tersitarios 43}

esta situación corresponde a las campañas contra el uso de agroquímicos llevadas a cabo en la localidad de Sebastián Elcano (departamento Río Seco) (Salizzi, 2019). Por el contrario, los conflictos más resonantes de los que se tiene registro surgen de la disputa por la propiedad de la tierra, que ha atraído recurrentemente la atención de los medios de comunicación locales y regionales. Teniendo en cuenta esto, el artículo amplía su atención a las acciones impulsadas en el marco del proceso de discusión, sanción y reglamentación del Ordenamiento Territorial de Bosques Nativos (OTBN), que, si bien se concentraron fuera del área de estudio (en la ciudad de Córdoba), contaron con la participación de representantes locales.

El artículo se estructura en cuatro apartados. En primer lugar, con intención de introducir el caso de estudio, se caracteriza la situación general de los departamentos del norte cordobés (Río Seco, Sobremonte y Tulumba). Luego, se describe el proceso de deforestación al que se vieron sometidos desde inicios de la década de 2000. En tercer lugar, se analiza la disputa de intereses que puso de manifiesto la discusión, sanción y reglamentación del OTBN de la provincia de Córdoba. Finalmente, se analiza la situación actual de los bosques nativos del norte provincial, considerando las perspectivas que enfrentan en relación con la normativa vigente.

La actualidad de la temática se enmarca en un contexto provincial en el que se encuentra cumplido el plazo de cinco años estipulado por la ley nacional para la actualización del $\mathrm{OTBN}^{1}$ y se discute su revisión a partir de la publicación en 2016 del anteproyecto de ley de Ordenamiento Territorial de Bosques Nativos y Regulación de Bosques Exóticos de la Provincia de Córdoba (Exp. 20811/L/16).

\section{Los departamentos del norte cordobés}

Si consideramos una escala de análisis centrada en el nivel continental, los departamentos del norte cordobés (Río Seco, Sobremonte y Tulumba) comprenden el extremo meridional del Gran Chaco americano (figuras 1 y 2), que abarca cerca de 1 millón de $\mathrm{km}^{2}$ que se extienden sobre parte de los territorios de Argentina, Bolivia, Paraguay y, en menor medida, Brasil. Se trata de la tercera ecorregión de Latinoamérica de acuerdo con sus dimensiones, y uno de los repositorios de biodiversidad más relevantes de la región en relación con su amplia variedad de ambientes, entre los que se destacan los bosques, pastizales y humedales (Morello \& Rodríguez, 2009). Dado su potencial agrícola, constituye en la actualidad una de las ecorregiones más amenazadas del mundo, encontrándose protegida solo un 9\% de su superficie (Kuemmerle et al., 2017). El $50 \%$ de su extensión se concentra en Argentina, donde se encuentra además la mayor parte del terreno convertido a usos agropecuarios (Morello et al., 2009). 
Figura 1. Ubicación del área de estudio
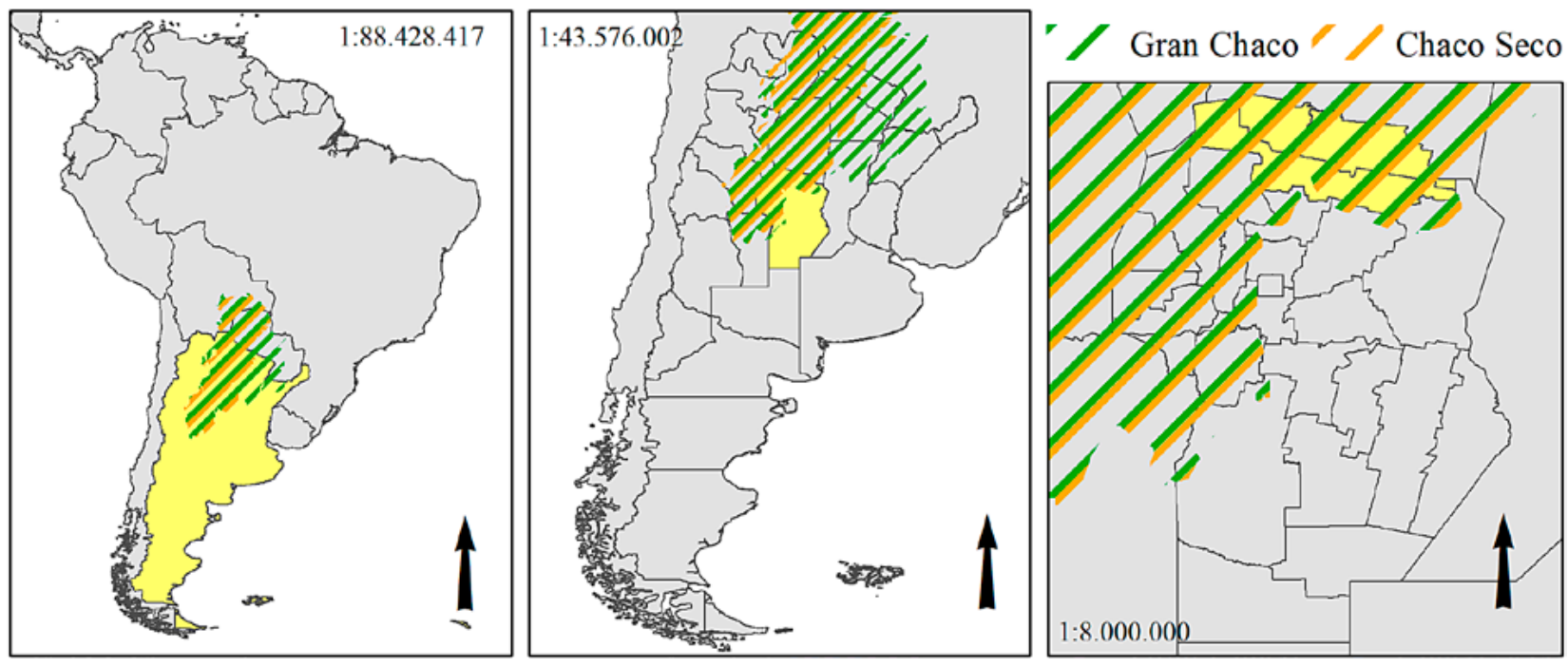

Fuente: elaboración del autor a partir de la cartografía provista por la Redaf (2019).

Figura 2. Departamentos del norte cordobés

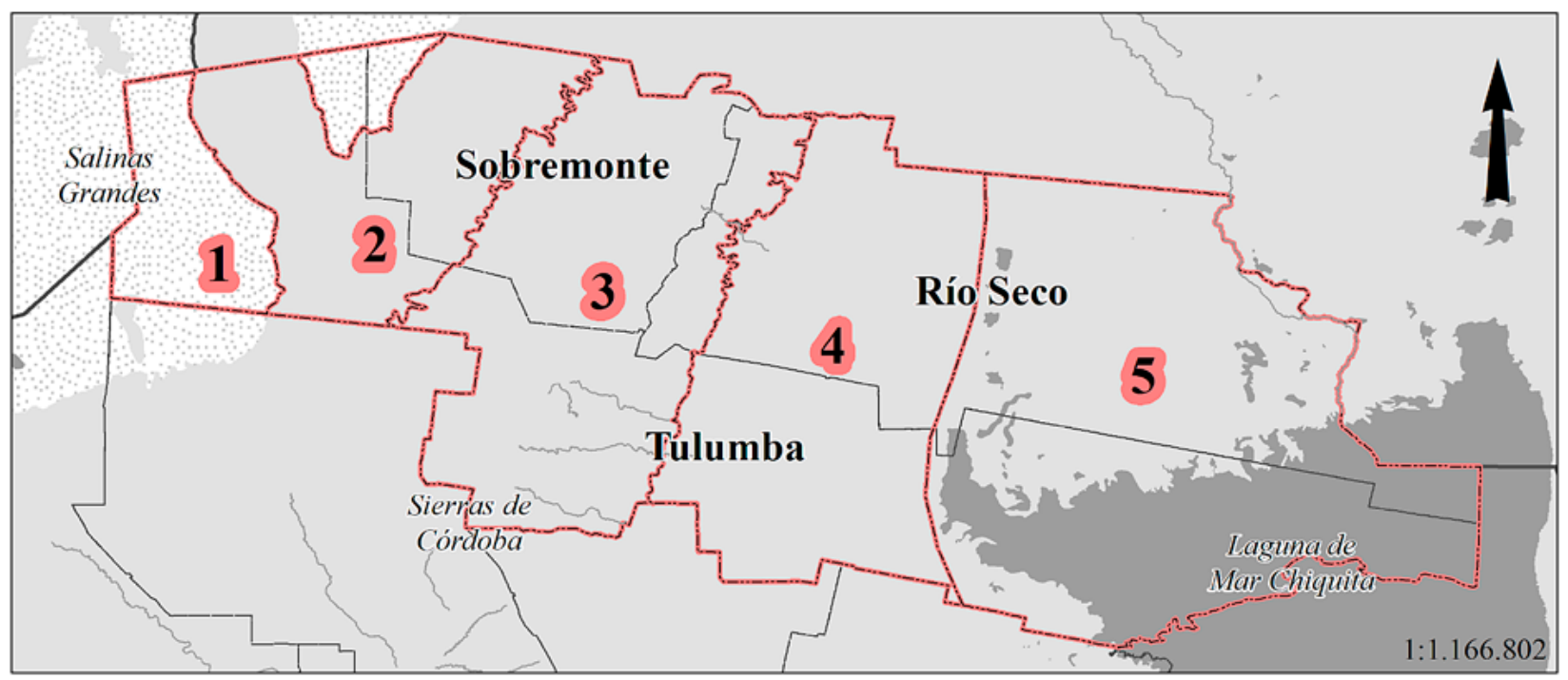

Referencias: 1) Salinas Grandes, 2) planicie occidental, 3) sistema serrano, 4) planicie oriental, 5) depresión de Mar Chiquita. Fuente: elaboración del autor a partir de Cabido y Zak (1999). 
Los departamentos analizados se encuentran en la porción occidental de esta gran ecorregión, que se denomina Chaco Seco debido a la influencia del gradiente pluviométrico, decreciente en sentido este-oeste. Se trata de una vasta llanura sedimentaria, que originalmente se hallaba cubierta por vegetación adaptada a condiciones de aridez, fundamentalmente bosques xerófilos y parches de pastizales (Torrella \& Adámoli, 2006). Al igual que el resto de la región, afronta hace décadas un proceso de degradación basado en el uso no planificado de sus recursos naturales, cuyas principales expresiones son: i) la explotación forestal selectiva, con gran incidencia en la primera mitad del siglo XX (Cozzo, 1992; Zarrilli, 2000); ii) la ganadería extensiva, con manejos silvopastoriles inadecuados (Saravia Toledo et al., 1985; Totino \& Morello, 2013); y, más recientemente, iii) el avance de la frontera agrícola, que en el caso del norte cordobés involucró tasas anuales de deforestación con valores que se ubican entre los más altos del mundo (Cabido \& Zak, 2010).

La expansión de la agricultura moderna sobre los ambientes del Chaco Seco, basada en la introducción del cultivo de commodities agrícolas y ganadería intensiva, ha implicado el reemplazo de grandes extensiones de bosques, que no solo condujo a la fragmentación y pérdida de hábitats y especies (Cabido, 2008), sino también al desplazamiento de los pequeños productores familiares (campesinos y población indígena) que vivían de sus recursos (Gorenstein \& Ortiz, 2016).

A partir de las entrevistas realizadas a representantes de diversos sectores de la sociedad local (considerando el amplio espectro de los productores locales y sus organizaciones, los organismos públicos vinculados al sector agropecuario con incidencia en la zona y las organizaciones sociales que representan a los campesinos y pequeños productores), puede afirmarse que la deforestación de las áreas boscosas constituye una de las consecuencias ambientales más reconocidas en el norte cordobés en relación con el proceso de expansión territorial del modelo productivo de los agronegocios. Esto sucede a pesar, incluso, de que la devastación del bosque chaqueño comprende una problemática que cronológicamente se inició antes de la introducción de cultivos extensivos en el área de estudio. La radicalidad de la nueva etapa de desmontes, que empezó en los años 1990 y fue profundizada a comienzos de la década siguiente, puso prácticamente fin a los remanentes de bosque que se encontraban en la zona, completando el proceso de degradación iniciado en la primera mitad del siglo XX.

Como fue señalado en trabajos previos (Salizzi, 2018a), el avance de la frontera agraria moderna sobre los departamentos del norte cordobés presenta una temporalidad que puede ser periodizada en dos momentos principales. El primer período, que representa el inicio de la expansión del 
modelo productivo de los agronegocios sobre el norte cordobés, es denominado transición mixta (de 1991 a 2001), en referencia a la incorporación combinada de ganado bovino y agricultura. Y el segundo es llamado agriculturización del norte cordobés (de 2001 en adelante), en función del reemplazo de la ganadería por cultivos agrícolas (principalmente soja y maíz) y la incorporación de ganadería intensiva.

En relación con los alcances del proceso iniciado en 1990, el representante del Ministerio de Agricultura y Ganadería de la provincia de Córdoba (MAyG) para los departamentos del norte cordobés reconocía esos años como el inicio de una gran deforestación que, si bien fue parcialmente controlada, dejó prácticamente sin montes. Con respecto a este tema indicaba que

$[\ldots]$ antes $[\ldots]$ se trabajaba con la Ley Forestal 8066 y se le exigía a cada productor que iba a desmontar su campo que haga su proyecto y sea aprobado, y se le revisaba todo. Primero por el $10 \%$ de las reservas, después hasta un $30 \%$, se le controlaba todo, se le daba la autorización a través de una resolución [...] y qué hicieron después ellos, sacaron las reservas, $o$ vinieron de afuera y prefirieron pagar una multa y volteaban todo. Voltearon las reservas (representante del MAyG, 2015).

La Ley Provincial 8066 (de Bosques y Tierras Forestales), que a partir de 1991 reglamentó el uso de las áreas boscosas, habilitaba la deforestación de parcelas de bosque nativo con fines agrícolas y ganaderos cumpliendo una serie de requisitos - entre los que se encontraba la presentación ante la autoridad forestal de un plan de trabajo acorde con las pautas fijadas por la reglamentación-e imponía sanciones que se basaban en el cobro de multas. La normativa buscaba controlar los desmontes iniciados en las décadas previas, impulsados por la adopción de cultivos forrajeros (ganadería bovina). Sin embargo, los años noventa están marcados por una nueva transformación productiva basada en la llegada de productores pampeanos que destinan sus inversiones a la ganadería (sobre forrajes cultivados) y a la agricultura, sentando las bases para el proceso de agriculturización del norte cordobés. Se trata de productores con altos niveles de capitalización que, en un contexto caracterizado por el escaso valor de la tierra y subsidiados por los beneficios arrojados por la producción agrícola pampeana, hicieron fácilmente frente a las multas y pusieron de manifiesto las limitaciones de la ley.

Esta situación se contraponía a la de los productores familiares locales, para quienes las normas establecidas significaban una restricción infranqueable. Al respecto, un productor ganadero del paraje Victoria Este (departamento Río Seco) señalaba: “[...] siempre fue un poco embromado para los que nacimos acá, para los que somos de la zona, siempre a los que venían de afuera les daban, compró 1000 hectáreas de campo y, bueno, lo peló 
${ }^{2}$ El modo en el que se integran estos factores $y$ su influencia sobre el proceso de ocupación de tierras para uso agropecuario se aborda con mayor profundidad en Salizzi (2017).

${ }^{3}$ Monitorea los desmontes realizados en el Chaco Seco a lo largo del periodo 19762012, a través del análisis y comparación de imágenes satelitales (Landsat).

\section{territarias 43}

todo. Pero a nosotros no, se nos fueron dando de a 5 hectáreas. Cinco hectáreas, 10 hectáreas, yo por ahí tengo todavía los permisos que se nos daba en 1990/1995. De a 5 hectáreas, por eso siempre estuvimos limitados [...]" (productor familiar capitalizado 1, 2015).

El contrapunto indicado representa un factor de relevancia para el análisis del proceso de deforestación reciente, así como de la disputa de intereses en torno a la sanción del OTBN. Se reconoce, por un lado, la situación de los productores empresariales, que desmontan extensas áreas de bosque para su conversión a cultivos; $\mathrm{y}$, por otro, la de los pequeños y medianos productores familiares que incorporan al monte dentro de sus actividades, estableciendo diferentes niveles de intervención (extracción de leña, desmontes selectivos, raleos, etc.).

\section{El proceso de deforestación del norte cordobés}

Con posterioridad a la crisis económica de 2001 se produce en los departamentos del norte cordobés una aceleración del proceso de expansión territorial del modelo de producción agroindustrial. Entre los principales factores involucrados en la trasformación de los usos del suelo se encuentran: a) el cambio en las condiciones climáticas, a través de la ocurrencia de un ciclo húmedo; b) la transformación que experimenta la coyuntura económica nacional hacia la década de 2000 con motivo de la devaluación de la moneda respecto al dólar norteamericano; c) el incremento en el precio internacional de los commodities agrícolas (principalmente de la soja); y d) la incorporación de tecnología en los procesos productivos, tanto agrícolas como ganaderos. $^{2}$

El período que se inicia está caracterizado por la dinámica de reemplazo de los espacios destinados a la ganadería (bovina y caprina) por cultivos agrícolas (principalmente soja), así como por nuevos pulsos de deforestación que afectan los remanentes de bosque nativo y renovables. Tomando como referencia la información provista por el "Proyecto de monitoreo de deforestación en el Chaco Seco" (FAUBA et al., 2019), ${ }^{3}$ puede indicarse que los departamentos Río Seco, Sobremonte y Tulumba perdieron entre los años 2002 y 2016 cerca de 206612,8 ha de monte, el equivalente a 13774,2 ha por año (dando lugar a una tasa promedio anual de deforestación del 6,7\%).

Las figuras 3 y 4 ejemplifican las características asumidas por el desmonte de parcelas de gran tamaño entre los años 2002 y 2013 en el área conocida como planicie oriental, que atraviesa perpendicularmente los departamentos Río Seco y Tulumba - al este de las sierras de Córdoba- y concentra los suelos de mayor aptitud agrícola (ver figura 2). El sector indicado comprende desde la década de 1990 el escenario privilegiado de la expansión agraria en el norte cordobés. Este estuvo ocupado hasta el siglo Xx por bosques de 
quebracho blanco y colorado (Cabido \& Zak, 1999) que fueron prácticamente erradicados como consecuencia, primero, de la tala vinculada al desarrollo de la red ferroviaria y, posteriormente, a la ampliación de la superficie destinada a los cultivos.

Figura 3. Parcelas desmontadas entre 2002 y 2013 en cercanías de la localidad de Los Hoyos (Río Seco) (más de 700 ha)

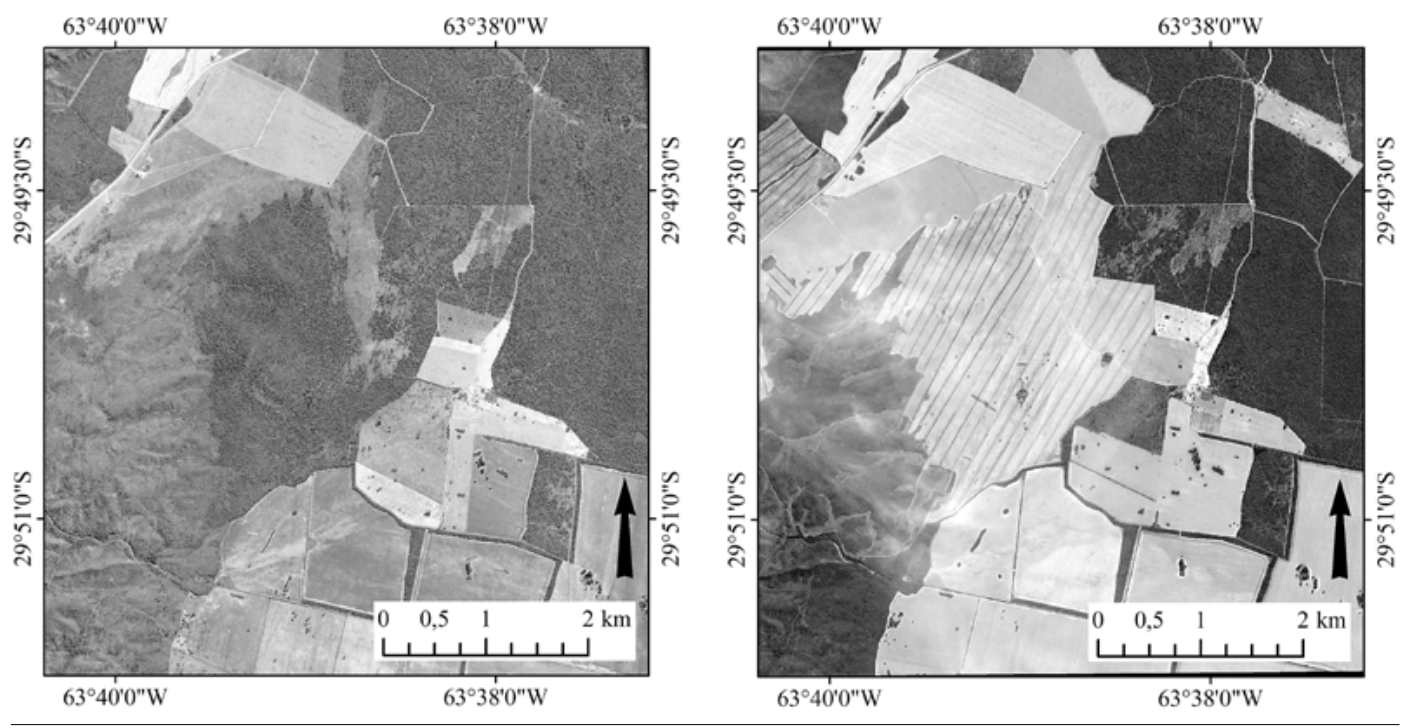

Fuente: Google Earth (2016).

Figura 4. Parcelas desmontadas entre 2002 y 2013 en el paraje Campo Grande (Río Seco) (más de 600 ha)

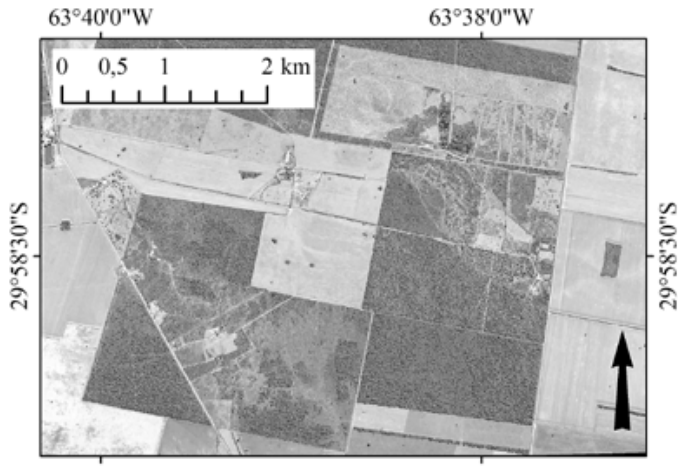

$63^{\circ} 40^{\circ} 0^{\prime \prime} \mathrm{W}$

$63^{\circ} 38^{\circ} 0^{\prime \prime} \mathrm{W}$

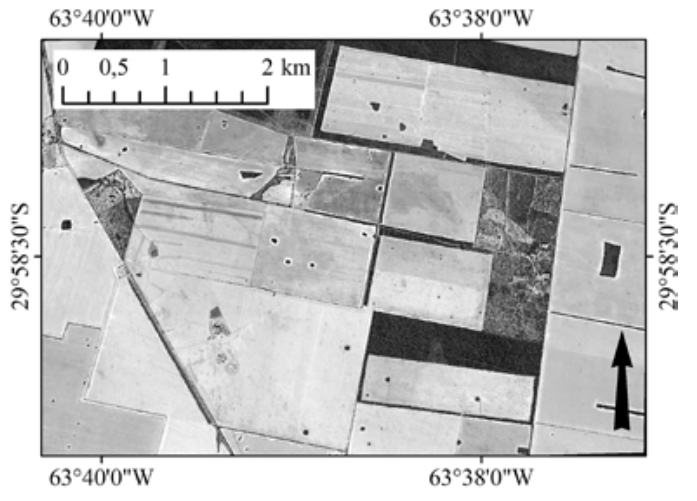

$63^{\circ} 40^{\prime} 0^{\prime \prime} \mathrm{W}$ territarias 43 
Las imágenes dan cuenta de una radical transformación en los usos del suelo, donde las actividades tradicionales, vinculadas a la ganadería extensiva (bovinos y caprinos) y a la obtención de leña y carbón del monte, fueron reemplazadas por la agricultura de secano (soja y maíz) en combinación con ganadería intensiva (adopción de feedlots).

A continuación, se analiza el modo en el que evolucionaron los desmontes en cada uno de los departamentos estudiados. La reconstrucción de esta progresión está orientada, adicionalmente, a facilitar una primera aproximación al modo en el que la sanción del OTBN (en 2010) influyó sobre dicho proceso. Para llevar a cabo esta tarea se presentan las figuras 5 y 6 , en las que: i) se describe la evolución anual de la superficie total desmontada, indicando la participación desagregada de cada uno de los departamentos (figura 5); y ii) se compara el volumen anual de los desmontes con la dinámica exhibida por el total acumulado (figura 6).

A través de la figura 5 se observan dos tendencias principales, relacionadas con los niveles de desagregación en los que se presenta la información:

i) A nivel departamental, se aprecia una distribución heterogénea de los desmontes que puede asociarse a una hipotética línea de avance de la frontera agraria moderna, cuya orientación predominante es hacia el norte y este

Figura 5. Evolución anual de la superficie desmontada (2002-2016)

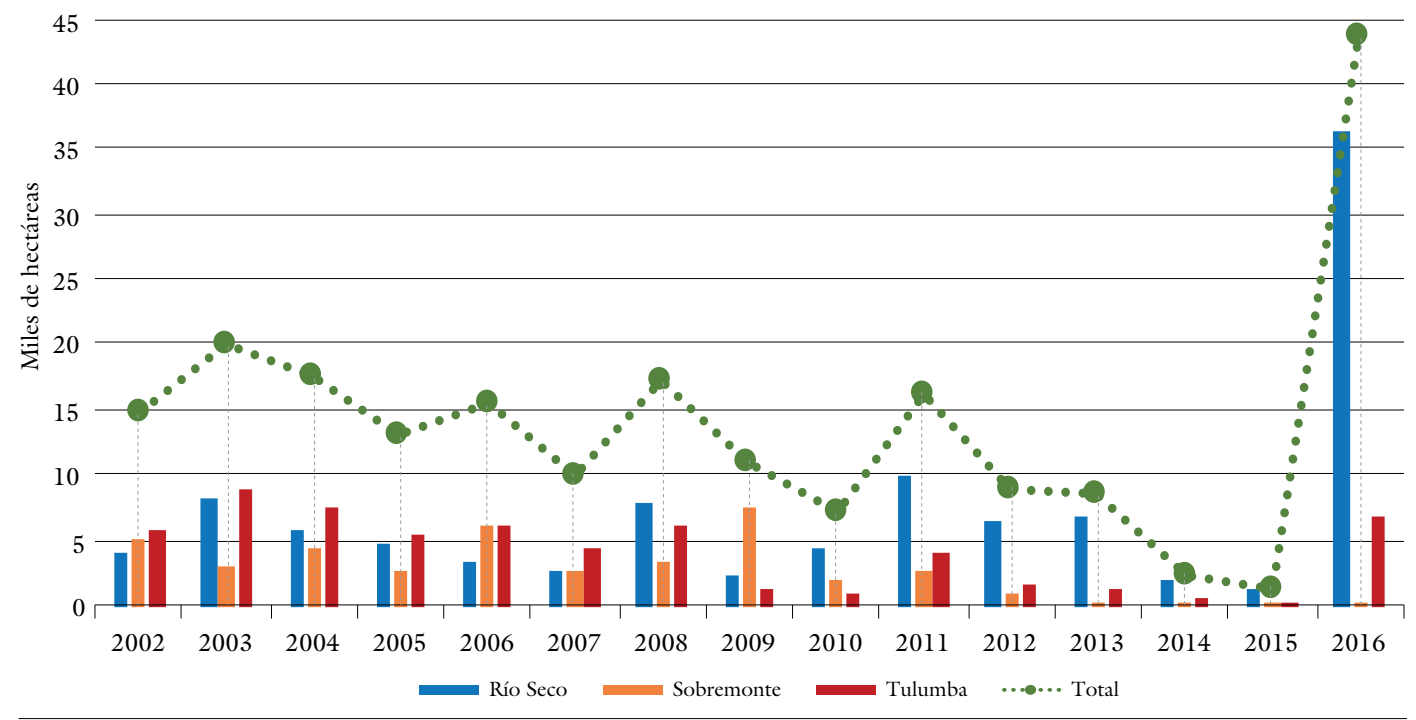

\section{territarios 43}

Fuente: elaboración del autor a partir de la información provista por el "Proyecto de monitoreo de deforestación en el Chaco Seco" (FAUBA et al., 2019). 
de los departamentos bajo estudio. Al inicio del período se manifiesta una primacía relativa del departamento Tulumba (seguido por Río Seco), que luego se modera y finalmente se revierte con la puesta en marcha del OTBN (2010) a través de la concentración de las tareas de desmonte en Río Seco. Más concretamente, estas se ubican en el amplio sector de montes bajos que comprende el área de transición hacia los pastizales de la depresión de Mar Chiquita (ver figura 2), que fue deliberadamente excluido de los espacios protegidos por la ley.

ii) A nivel del conjunto de los departamentos, desde 2003 se evidencia un decrecimiento general en el total de hectáreas desforestadas, a excepción del año 2016 cuando se produce un profundo incremento impulsado por Río Seco. En relación con esta tendencia, se considera que expresa el progresivo agotamiento de las áreas de monte ubicadas en sectores de interés para la expansión agropecuaria, de acuerdo con sus aptitudes agroecológicas y el posterior avance sobre sectores hasta el momento considerados marginales. Teniendo en cuenta esto, resulta interesante considerar los picos de deforestación producidos en los años 2008, 2011 y 2016. Estos se encuentran directamente vinculados a la conformación de la Comisión de Ordenamiento Territorial de Bosques Nativos (COTBN) en 2008, que abre la discusión en torno a la definición del OTBN; la sanción de la ley provincial en 2010; y el cumplimiento en 2016 del plazo que establece la legislación nacional para la revisión y actualización de los ordenamientos provinciales. Se trata, en efecto, de desmontes realizados en tres momentos claves del proceso legal: a) antes de que comenzara a discutirse el proyecto; b) previamente a que se pusiera en práctica la ley; y c) una vez cumplido el plazo para su actualización.

En términos cuantitativos, a partir de la reglamentación del OTBN en $2011^{4}$ se observa una drástica reducción de los desmontes, que los conduce en 2015 a valores cercanos al $9 \%(1338,97 \mathrm{ha}) \mathrm{de}$ los alcanzados en 2002 (14721,23 ha). Esta tendencia se revierte en 2016 cuando, tomando como referencia el mismo año, se eleva al $295 \%$ ( 43473,50 ha).

La figura 6 permite tener una visión más extendida de cómo la disminución del total de hectáreas desmontadas conduce con posterioridad a la reglamentación del OTBN a una progresiva desaceleración del proceso de deforestación, así como también evidencia la magnitud de las transformaciones relevadas hacia el fin del período analizado. En ella puede observarse que el total de hectáreas deforestadas prácticamente detiene su crecimiento entre 2013 y 2015, para manifestar luego un nuevo impulso que lleva al total acumulado en 2016 por sobre las 200000 ha.
${ }^{4}$ Se reglamentó a través del Decreto Provincial $170 / 11$.

territarias 43 11 


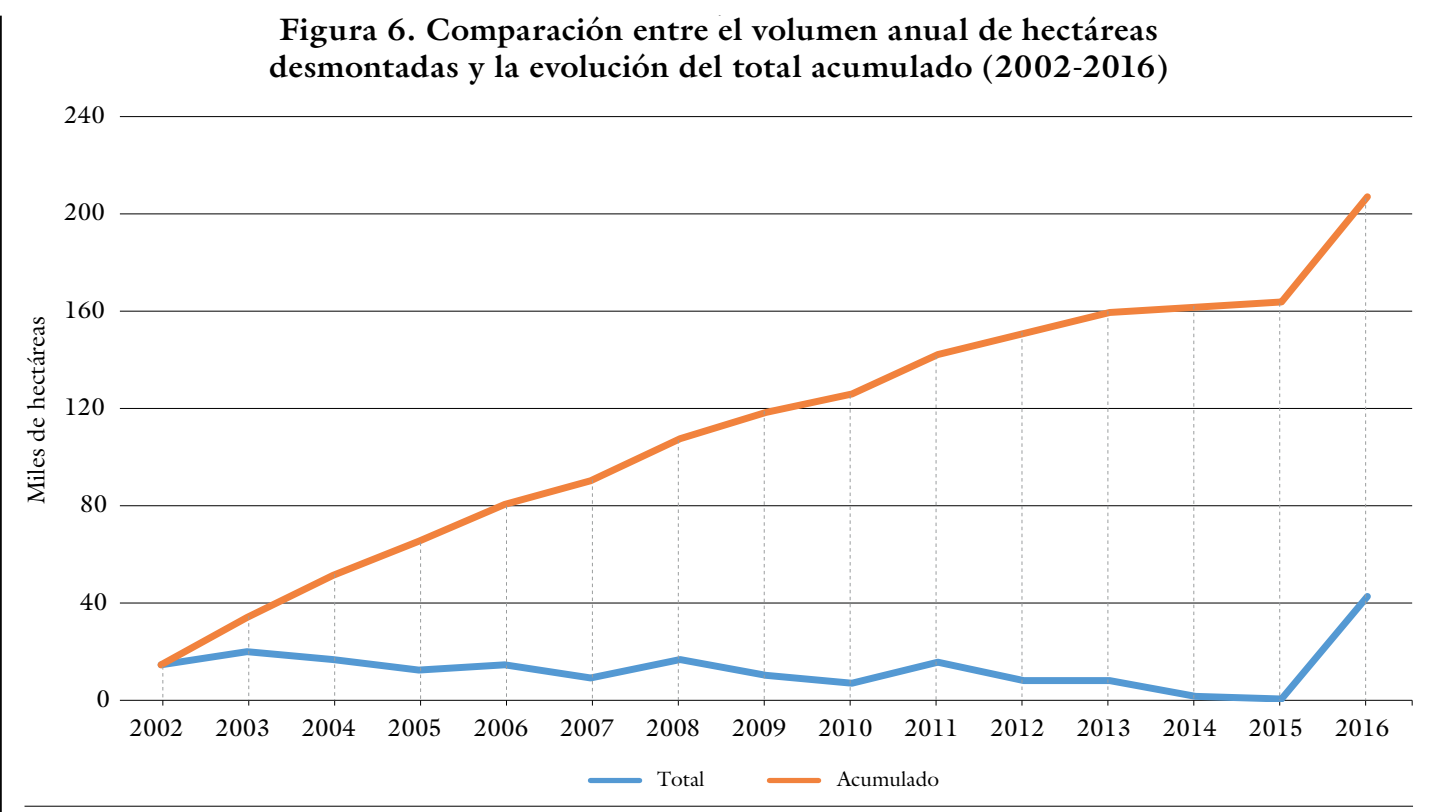

Nota: debe tenerse en cuenta que el valor acumulado indicado para el año 2002 responde a una abstracción metodológica, dado que, si se toma en cuenta la serie completa, iniciada en el año 1976, el acumulado total alcanza las 374566,38 ha.

Fuente: elaboración del autor a partir de la información provista por el "Proyecto de monitoreo de deforestación en el Chaco Seco" (FAubA et al., 2019).

En términos generales, puede indicarse que la implementación del OTBN logró moderar temporalmente la deforestación hasta el año 2016, aunque para ese entonces ya se había producido una creciente pérdida de activos forestales como consecuencia de su reemplazo por forrajes implantados y cultivos de secano (principalmente soja). Así mismo, a pesar de los controles establecidos, continuaron desforestándose parches y relictos de bosque. En este sentido, un pequeño productor ubicado al norte del paraje Encrucijadas (departamento Río Seco) manifestaba: "El otro día estaban sacando plantas grandes, cuando vino la Policía a averiguar, era un hombre de acá de La Cañada, que le dicen, que las sacaba de raíz. Y si no van volteando con el mismo tractor y después largan fuego, aran y siembran ahí nomás la soja" (pequeño productor familiar 1, 2015).

A través de este mecanismo los grandes productores continúan encontrando la forma de ampliar el área que destinan a la producción agrícola, que en la actualidad avanza hacia el este de la planicie oriental. La figura 7 permite ubicar los sectores donde se concentran los desmontes desde la década de 1990, así como el área protegida a través del OTBN. 
Figura 7. Áreas de bosque protegidas y desmontes en el norte cordobés

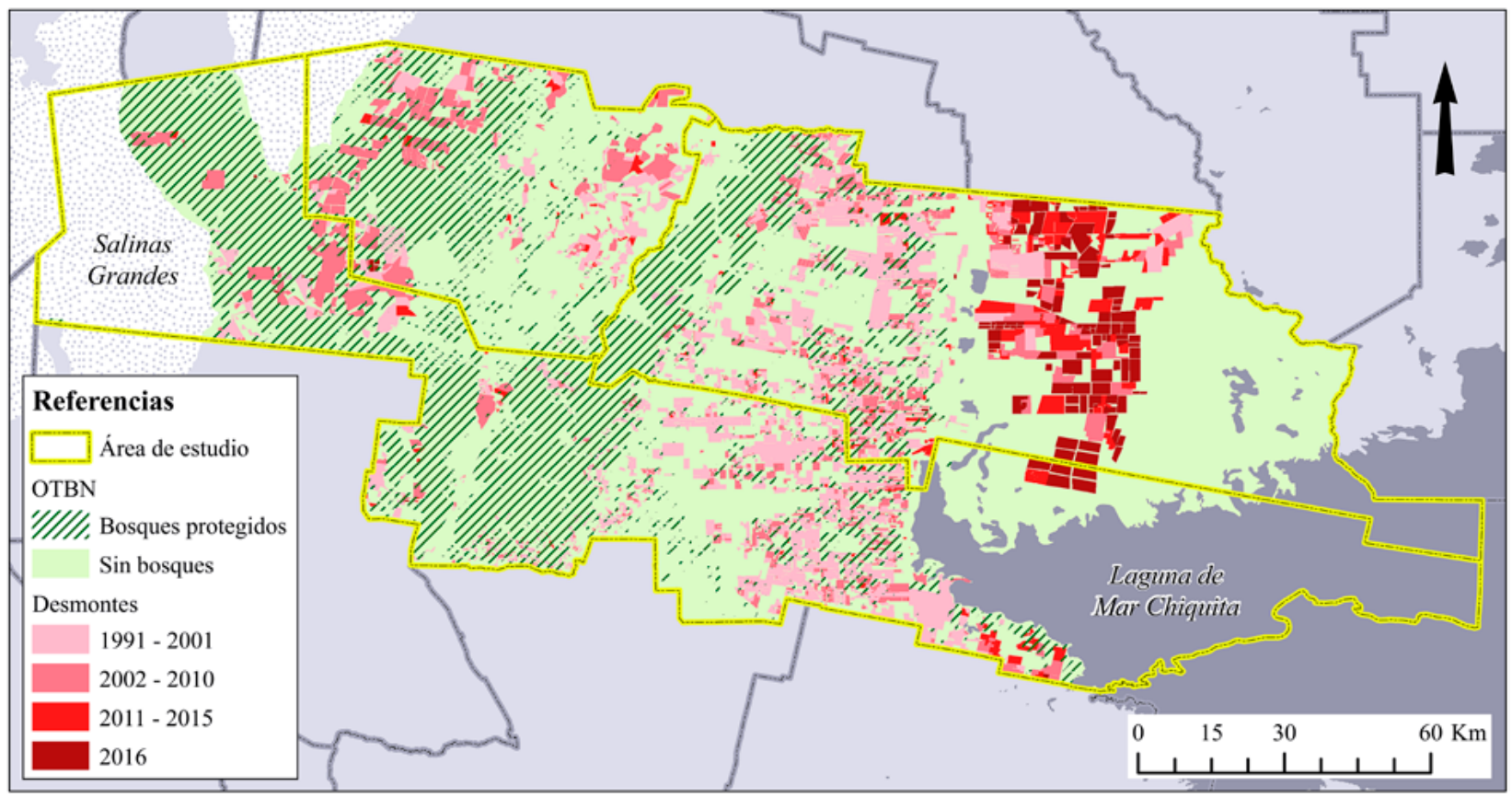

Fuente: elaboración del autor a partir de la información provista por el Ministerio de Agua, Ambiente y Energía de la provincia de Córdoba y el "Proyecto de monitoreo de deforestación en el Chaco Seco" (FAUBA et al., 2019).

Teniendo en cuenta la temporalidad de los desmontes y la extensión del área sujeta a conservación a través del OTBN, puede señalarse que:

i) La deforestación que afectó el sector central del área de estudio (planicie oriental) se realizó predominantemente con anterioridad a 2001 , en vinculación con la introducción de pasturas y el incremento progresivo del área sembrada con cultivos anuales. En efecto, la posterior agriculturización de los predios se basó, fundamentalmente, en un cambio en la actividad a la que se destinaban.

ii) Los desmontes iniciados con posterioridad a 2001, cuando se generaliza la producción agrícola en la planicie oriental, se concentran en otros sectores del área de estudio: la planicie occidental, la depresión de Mar Chiquita y, en menor medida, el sistema serrano (ver figura 2). La transformación de estas áreas se encuentra asociada a la implantación de pasturas, impulsada por la relocalización de la ganadería bovina - que se vio arrinconada-, y la territarias 43 
incorporación de cultivos en las zonas agroecológicamente aptas.

iii) Se destaca la reciente ampliación de los desmontes sobre el sector de transición hacia la depresión de Mar Chiquita, donde se concentra el proceso de deforestación con posterioridad a la reglamentación del OTBN (2011). En este marco, es notoria la magnitud que alcanza en 2016, avalado por la legislación vigente.

iv) El gran tamaño de las parcelas desmontadas con posterioridad a 2010 en la depresión de Mar Chiquita permite alcanzar una idea del nivel de concentración que presenta la propiedad de la tierra en el área de estudio. Se trata de un acotado grupo de grandes empresarios que hegemonizan la producción agropecuaria.

v) Se constata, a pesar de la vigencia del OTBN, la realización de desmontes en áreas de conservación. Esta situación se manifiesta por medio de la superposición del área protegida por la ley y los polígonos correspondientes a los desmontes realizados con posterioridad al año 2010.

Ahora bien, habiendo señalado los alcances del proceso de deforestación al que se vio sometida recientemente el área de estudio e introducido los principales efectos generados por el OTBN, se avanza a continuación sobre el análisis de las disputas en torno a la formulación y sanción de la legislación. El orden elegido, que no respeta la secuencia cronológica de los sucesos, se basa en la necesidad de introducir el análisis sobre la base de un conocimiento acabado del proceso de deforestación, solo de ese modo podrán contextualizarse las decisiones tomadas por los sectores sociales involucrados (Estado, productores empresariales, productores familiares, entre otros) y evaluar los alcances de sus propuestas y acciones.

\section{La disputa de intereses en torno al OTBN}

Una de las manifestaciones más significativas que adoptó la incompatibilidad entre los proyectos de ocupación y uso del espacio que se enfrentan a través del avance de la frontera agraria moderna en el norte cordobés corresponde a la disputa en torno a la elaboración y aplicación del OTBN. Esta puede ser situada temporalmente entre los años 2008 y 2010, aunque se extiende a la actualidad producto de la falta de consenso alrededor de la norma sancionada y del nuevo protagonismo que adquiere a partir del año 2016.

El OTBN es una legislación provincial sancionada en agosto de 2010 , orientada a reglamentar el uso de los bosques nativos existentes - cualquiera sea su origen y temporalidad-, que se encuentran diseminados por el territorio cordobés. Las principales áreas de influencia de la normativa son el norte y el oeste provincial, donde se concentran las áreas cubiertas por bosques. 
El proceso para la creación del OTBN de la provincia de Córdoba ${ }^{5}$ se inició con posterioridad al año 2007, cuando se sancionó a nivel nacional la Ley 26331 — denominada Ley de Presupuestos Mínimos de Protección Ambiental de los Bosques Nativos (popularizada como Ley de Bosques) - con la finalidad de promover el enriquecimiento, restauración, conservación, aprovechamiento y manejo sostenible de los bosques nativos del país. Entre sus puntos principales, la legislación nacional estableció a partir de su reglamentación en 2009 un plazo máximo de un año para que las provincias definieran el ordenamiento territorial de sus bosques nativos. ${ }^{6}$ Dicha tarea debía ser desarrollada mediante un proceso participativo, que permitiera determinar, siguiendo los criterios de sustentabilidad establecidos por la ley nacional, las diferentes categorías de conservación en función del valor ambiental de las unidades de bosque nativo y de los servicios ambientales que prestan (Ley Nacional 26331, art. $6^{\circ}$ ). En ella se indicaba, además, que toda intervención de los bosques nativos debía contar con una planificación de las actividades, enmarcada en el Programa Experimental de Manejo y Conservación de los Bosques Nativos (Res. 256/09), que administra los fondos de compensación (Dirección de Bosques, 2017a).

En términos generales, la sanción de la ley nacional, a través de los ordenamientos establecidos por las provincias en los años sucesivos, condujo a una disminución de los desmontes. Sin embargo, no los detuvo por completo, ya que continuaron realizándose no solo en áreas que no fueron categorizadas como bosques nativos, sino también en los espacios donde su práctica se encontraba prohibida. De acuerdo con la información estadística elaborada por la Secretaría de Ambiente y Desarrollo Sustentable de la Nación (SAyDS), la superficie anual deforestada se redujo entre 2007 y 2016 de 728233 a 136473 ha, alcanzando, no obstante, un acumulado de casi 2,4 millones de ha desde la sanción de la norma (Dirección de Bosques, 2017b).

La provincia de Córdoba sancionó su OTBN recién en el año 2010, por medio de la Ley 9814 (de Ordenamiento Territorial de Bosques Nativos de la Provincia de Córdoba), luego de una serie de instancias participativas que se vieron reflejadas parcialmente en el contenido final de la norma (Silvetti et al., 2013; Vera, 2015). Según el relevamiento realizado por la SAyDS, su implementación produjo una reducción en la pérdida de tierras forestales, que en términos generales pasó de 39936 ha en el período 2008-2011 a 7765 ha en el cuatrienio 2012-2015 (Dirección de Bosques, 2017b). ${ }^{7}$

Las instancias participativas para la discusión del proyecto de ley se iniciaron en 2008, cuando en el ámbito de la Secretaría de Ambiente de la provincia de Córdoba se conformó la Comisión de Ordenamiento Territorial de Bosques Nativos (COTBN). Siguiendo los lineamientos de la
${ }^{5}$ La reconstrucción de los momentos atravesados por el proceso de elaboración y sanción de la Ley 9814 , así como la participación de los diferentes sectores sociales involucrados, fue realizada a partir del análisis de: entrevistas; información provista por el sitio web de la Coalición Argentina para la Iniciativa de Acceso (Coalición TAI Argentina), que formó parte de la COTBN y promovió la inclusión de articulos que asegurasen los 'principios de acceso' en la elaboración de la normativa; notas compiladas por el periodista especializado Dario Aranda (2015); notas publicadas en medios de comunicación (tradicionales $y$ alternativos); $y$ artículos de la revista de la Sociedad Rural de Jesús María (SRJM).

${ }^{6}$ En ese lapso las autoridades provinciales quedaban impedidas de autorizar desmontes $y$, una vez excedido este, se les probibia conceder cualquier tipo de utilización y/o aprovechamiento de los bosques nativos.

${ }^{7}$ La estadistica presentada toma como referencia las hectáreas desmontadas en las regiones forestales Parque Chaqueño y Espinal.

territorias 43 
${ }^{8}$ Es una entidad de segundo grado, sin fines de lucro, integrada por asociaciones rurales primarias de las provincias de Córdoba, La Rioja y Catamarca. Entre sus miembros se encuentra la Sociedad Rural de Jesús María (SRJM), una institución de gran influencia en el proceso de avance de la frontera agraria moderna sobre el norte cordobés (Salizzi, 2017).

${ }^{9}$ Dicho agrupamiento tomó notoriedad durante el conflicto iniciado en 2008 por la Resolución 125, que establecía un sistema de retenciones móviles para las exportaciones agropecuarias.

10 Sebastián Elcano (Rio Seco), Rio Cuarto (Rio Cuarto), Cruz del Eje (Ischilin), Ballesteros (Unión), Villa General Belgrano (Calamuchita), Villa Dolores (San Javier) y Rio Ceballos (Colón).

\section{territarias 43}

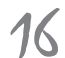

ley nacional, la Comisión estaba integrada por representantes de sectores gubernamentales y de la sociedad civil, entre los que se destacaban el Instituto Nacional de Tecnología Agropecuaria (INTA), ministerios y secretarías provinciales, gobiernos comunales y municipales, organizaciones sociales ambientales, universidades públicas - Universidad Nacional de Córdoba (UNC), Universidad Nacional de Río Cuarto (UNRC) y Universidad Nacional de Villa María (UNVM) - , universidades privadas, el Movimiento Campesino de Córdoba (MCC) y organizaciones gremiales del campo.

Las entidades rurales estaban comprendidas por las filiales provinciales de la Federación Agraria Argentina (FAA), la Sociedad Rural Argentina (SRA), la Confederación de Asociaciones Rurales de la Tercera Zona (Cartez), ${ }^{8}$ en representación de Confederaciones Rurales Argentinas (CRA), y la Confederación Intercooperativa Agropecuaria (Coninagro). Estos organismos forman parte de la Comisión de Enlace de Entidades Agropecuarias (Regional Córdoba), ${ }^{9}$ que progresivamente cobró protagonismo en la disputa.

Ya en esta instancia inicial comenzaron a manifestarse los primeros síntomas del conflicto entre las partes. En aquella oportunidad fue votada para presidir la Comisión Alicia Barchuk, especialista en Ciencias Agropecuarias e investigadora de la Universidad Nacional de Córdoba. Luego de la designación de las autoridades, y habiendo participado de dicha instancia, la
Cartez se retiró de la Comisión solicitando a la Secretaría de Ambiente que disolviese su composición por no considerarla representativa del conjunto. A pesar de esta primera polémica, centrada en quién ocuparía la presidencia de la Comisión, la COTBN siguió adelante con la discusión del proyecto de ley.

Luego de varios meses de trabajo, que incluyeron la realización de talleres regionales en siete localidades representativas de las principales cuencas hídricas de la provincia, ${ }^{10}$ en junio de 2009 la COTBN presentó formalmente el proyecto de ley a la Secretaría de Agricultura de la provincia de Córdoba. Sin embargo, la propuesta recién fue enviada a la Legislatura de la Provincia de Córdoba en el mes de octubre, cuando se elevó también otro proyecto efectuado por la Cartez (ya por fuera de la Comisión). De este modo, la Secretaría de Ambiente, incumpliendo los criterios establecidos por la normativa, no elevó un proyecto de ley, sino dos propuestas distintas, que de todos modos comenzaron a ser tratadas por la Comisión de Asuntos Ecológicos (CAE) de la Legislatura a fin de elaborar el anteproyecto.

Tras una serie de instancias participativas coordinadas por la CAE — en las que recibió a representantes de la COTBN, la Cartez, la Secretaría de Ambiente y el MCC-, sus miembros decidieron formular la propuesta de ley sobre la base general del documento elaborado por la COTBN. No obstante, un día antes de que fuera tratada por la cámara, legisladores del oficialismo 
incorporaron un nuevo proyecto cuyo contenido se distanciaba tanto del que había sido consensuado en la COTBN como de la reformulación elaborada por la CAE que finalmente fue el aprobado el 4 de agosto de 2010. A través de este particular itinerario, y a pesar de los reclamos hechos por las instituciones y organizaciones que formaban parte de la COTBN, se sancionó la Ley 9814 , por medio de la cual la provincia se adhería formalmente a la Ley de Bosques.

La ley promulgada fue el resultado de las presiones ejercidas por las entidades del campo, encabezadas por la Cartez, que lograron instalar un proyecto que, en un escenario que se mostraba desalentador, estuviera relativamente acorde con sus intereses. Para esta tarea contaron, a su vez, con el apoyo clave de instituciones públicas de peso, como el MAyG, y de legisladores por el oficialismo que viabilizaron la presentación del proyecto y lo transformaron en ley.

En este marco, tanto a lo largo del proceso como una vez finalizado, la Unión Campesina del Norte (Ucan), central campesina con influencia en los departamentos Río Seco, Sobremonte y Tulumba, participó activamente de las acciones e instancias de movilización que convocó el MCC. Estas se concentraron predominantemente en la ciudad de Córdoba (capital de la provincia), donde el objetivo central de los reclamos fue la legislatura.

Entre las críticas que recibió la norma sancionada se destacan: i) la demora con la que fue tratada y aprobada, una vez que la mayor parte del bosque ya había sido afectado, como se mostró anteriormente, por el proceso de deforestación; ii) el hecho de que no se hayan respetado las instancias formales establecidas por la ley nacional para la formulación del proyecto y su tratamiento; y iii) las profundas transformaciones que sufrió el texto presentado originalmente por la COTBN, que derivaron en una drástica flexibilización de las restricciones que establecía.

En cuanto a este último punto, los principales elementos objetados fueron: i) la habilitación del aprovechamiento sustentable de los terrenos comprendidos dentro de las zonas de mayor protección; ii) la eliminación de los controles sobre zonas con pendientes superiores al $5 \%$; y iii) la posibilidad de introducir desmontes en áreas "donde exista o se genere infraestructura para producción bajo riego". ${ }^{11}$

La SAyDS consideró que el OTBN de Córdoba poseía deficiencias técnicas y se negó a remitir los fondos comprendidos por la ley para compensar a los dueños de los predios con monte. Frente a esta situación el gobierno provincial dictó el Decreto 1131/12, que modificó los artículos del decreto reglamentario (170/2011) relativos a los temas cuestionados y estableció una nueva zonificación. De este modo, se introdujo un nuevo mapa de OTBN, que es el que actualmente rige para la autoridad nacional de aplicación, donde se contemplaban solo las áreas con bosque (en sentido estricto) y que,
${ }^{11}$ Son algunos de los señalamientos realizados por ambientalistas y cientificos que participaron de la COTBN en comunicaciones posteriores a la aprobación del OTBN (La Voz del Interior, 18/08/2010).

territorias 43 17 
12 Disponible en linea: http://www.traslasierranoticia.com.ar/ la-nueva-ley-bosquepedido-cartez-la-federacion-agraria-claramenteinconstitucional

\section{territarias 43} 18 si bien ampliaba la extensión de la zona considerada de alto valor de conservación (color rojo), redujo drásticamente la zona de mediano valor (color amarillo) (Vera, 2015, 2017).

Finalmente, cabe destacar que desde 2016 se encuentra cumplido el plazo estipulado para la actualización del OTBN y se discute su revisión desde la publicación del Proyecto de Ley de Ordenamiento Territorial de Bosques Nativos y Regulación de Bosques Exóticos de la Provincia de Córdoba (Exp. 20811/L/16), el cual es criticado por no haber surgido de un proceso participativo, tal como lo establece la ley nacional. Dan cuenta de este debate, y de las distintas posiciones que se enfrentan en él, el anteproyecto antes mencionado, la propuesta presentada por la Cartez (2016) y la respuesta elaborada por Kopta et al. (2016), de la que participaron miembros de la UNC y de diversas organizaciones sociales. En definitiva, la oposición a la revisión del OTBN movilizó nuevamente a toda la sociedad cordobesa, incluyendo desde 2016 diversas marchas y movilizaciones.

De acuerdo con las denuncias realizadas públicamente por el MCC, el nuevo proyecto promueve, entre otros puntos, la conversión de zonas que antes se consideraban de alta prioridad de conservación (rojas) a zonas de mediana prioridad (amarillas), habilitando tareas de rolado selectivo para la introducción de ganadería bovina. ${ }^{12}$ De esta forma, si en 2010 la estrategia de las entidades gremiales del campo frente al proyecto de la COTBN (así como con la sanción del Decreto 1131/12) consistió en quitar las zonas amarillas y transformarlas en verdes, reduciendo el nivel de las restricciones establecidas, actualmente consiste en pintar las rojas de amarillo para alcanzar el mismo resultado.

\section{Los departamentos del norte de Córdoba}

La reglamentación del OTBN en febrero de 2011 introdujo en los departamentos del norte cordobés una serie de situaciones que terminan de dar forma al problema de investigación que se analiza en el artículo.

En primer lugar, excluyó de las categorías de conservación sectores acotados del área de estudio, donde se concentraron los desmontes. La comparación del modo en el que se estructuran en el norte cordobés la zonificación propuesta originalmente por la COTBN y la que actualmente forma parte del OTBN (según la SAyDS) (figura 8) permite reconocer áreas concretas que finalmente fueron excluidas de la norma o categorizadas como de menor importancia de conservación.

La ley nacional establece tres categorías de conservación que distingue a través de los colores rojo (alto valor), amarillo (mediano) y verde (bajo). El color rojo comprende recursos forestales que no deben ser sujetos a aprovechamiento forestal, en los que solo pueden llevarse a cabo actividades que no alteren sus atributos (Dirección de Bosques, 2017a). Teniendo 
Figura 8. Comparación de las zonificaciones establecidas para el norte cordobés según el proyecto de la COTBN y el OTBN vigente (registrado en la SAyDS)
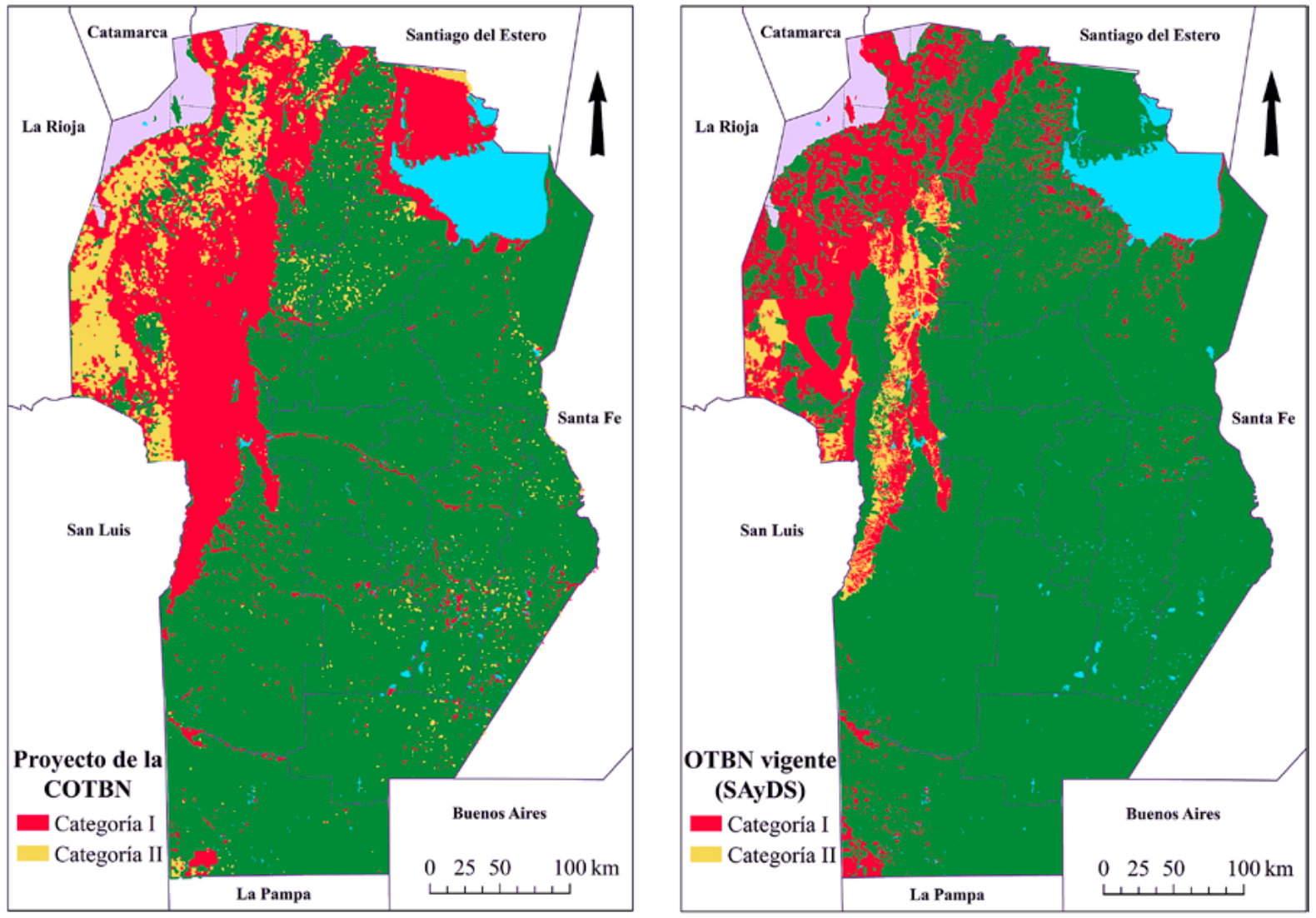

Fuente: elaboración del autor a partir de la cartografía provista por la COTBN (2009) y la Redaf (2019).

en cuenta esto, la figura 8 permite comprobar en el área de estudio:

i) La eliminación generalizada de las zonas correspondientes al color amarillo (mediano valor de conservación), que se ubicaban principalmente en el área serrana y la planicie occidental del norte cordobés (ver figura 2). ii) La vasta superficie que fue desafectada de las zonas de protección (color rojo y amarillo) en el este de los departamentos Río Seco y Tulumba.

Así, el OTBN de la provincia de Córdoba excluyó de sus categorías de conservación la vegetación ubicada en el área de la depresión de Mar Chiquita (ver figura 2), territarias 43 
debido a que los especialistas que redactaron el documento final consideraron que no se trataba de un estrato que pudiera ser considerado bosque por su carácter transicional hacia los pastizales ubicados en los bajos inundables. Dicho sector, si bien forma parte del área provincial protegida "Reserva de uso múltiple bañados del río Dulce y laguna de Mar Chiquita” y comprende desde 2002 uno de los espacios de protección de humedales suscriptos al Convenio de Ramsar (TSCW, 2018), es una de las zonas donde luego de 2011 se concentraron los desmontes producidos por la expansión de la frontera productiva. Se trata de un área de conservación que comprende la mayor cuenca endorreica del país, con un destacado valor ecológico relacionado con el número y diversidad de aves acuáticas y especies migratorias (Torrella \& Adámoli, 2006; Benzaquén et al., 2017).

En segundo lugar, la norma estableció una ralentización en el proceso de conversión de áreas forestales a cultivos de commodities agrícolas y ganadería intensiva, creando una reserva de tierras susceptible de ser incorporada en el futuro a la matriz productiva agroindustrial (Salizzi, 2017).

$\mathrm{Al}$ introducir un freno a los desmontes condujo a una desaceleración del proceso de avance de la frontera agraria moderna en el norte cordobés, exceptuando la zona de la depresión de Mar Chiquita, que se vio compensado por un nuevo desplazamiento de la agricultura moderna hacia el sur de la provincia de Santiago del Estero (Salizzi, 2018b). En este sentido, se habría producido un 'salto', motivado en la decisión de esquivar las trabas impuestas por la legislación. La búsqueda por concretar una revisión del OTBN, promovida por las entidades del campo (reunidas en torno a la Comisión de Enlace de Entidades Agropecuarias) y el gobierno provincial, no puede más que ser leída como un intento por dar un nuevo impulso al modelo productivo agroindustrial en la provincia.

Adicionalmente, es interesante recuperar la respuesta de un representante de la AER INTA Jesús María al momento de ser consultado por el modo en el que impactó la promulgación de la ley en los departamentos Río Seco, Sobremonte y Tulumba:

Demoró en sancionarse y no ha tenido un tratamiento claro, entonces hoy por hoy la Ley de Bosques está en una cuestión gris. No se dan permisos prácticamente de desmonte, y no hay, digamos, una definición. Lo único claro que hay es que hoy nadie puede tocar nada. $\mathrm{Y}$ ya es relativamente poco lo que queda con bosques, residual digamos de lo que había sido, puede estar quedando en el mejor de los casos menos del $10 \%, 8 \%$ del bosque inicial. Lo que había que hacer ya se hizo, y el que no lo hizo se quedó atrás con el tema de los desmontes (representante 1 de la AER INTA Jesús María, 2015).

\section{territarias 43}


En el fragmento citado se destaca la idea de que el estado de la ley es confuso y que, de todos modos, llegó tarde. En relación con este último punto, las palabras del entrevistado acerca de que "lo que había que hacer ya se hizo, y el que no lo hizo quedó atrás" son elocuentes. Estas dan cuenta, a su vez, de una valoración ambigua en torno a los desmontes y la sanción del OTBN. Por un lado, admite la pérdida generalizada de activos forestales; por otro, reconoce que la norma habría establecido un parteaguas en torno a la posibilidad de realizar desmontes. Esta última afirmación, que parecería ser una obviedad, es relevante en la medida en que está relacionada con la capacidad que tienen los productores locales para realzar sus actividades. Si bien es claro que para los productores agrícolas la imposibilidad de deforestar representa una limitación, no debe perderse de vista que los productores familiares capitalizados encuentran en las restricciones para intervenir el monte dificultades adicionales para continuar con sus prácticas.

Esta situación es esgrimida por las entidades del campo, como la SRJM, para presionar al gobierno provincial en relación con una flexibilización de la norma. En cuanto a la ganadería bovina, el representante de la SRJM en Villa de María del Río Seco expresaba:

Cómo intervenir el bosque, que no es sacarlo... A veces, vos para la ganadería tenés que intervenirlo. Se hace el desmonte selectivo, se dejan 100/150 árboles por hectárea, el algarrobo, el quebracho blanco, o sea, el árbol, y sacar el churqui, el fachinal, que no permite que se desarrolle el pasto, no lo come el animal eso, pasa a ser improductivo y cuando se seca es el principal material combustible, y quema todo. [...] Pero hoy no se puede intervenir (representante de la SRJM en Villa de María del Río Seco, 2015).

La SRJM (en el seno de la Comisión de Enlace de Entidades Agropecuarias) ha desarrollado desde la sanción de la ley una serie de acciones que tienen como finalidad impulsar su modificación (asambleas con miembros de la organización, consultas abiertas a productores locales y participación en movilizaciones a la Legislatura de Córdoba y en paros ganaderos organizados por la Comisión de Enlace). Entre los principales argumentos esgrimidos aseguran que el OTBN vigente atenta contra lo que definen como "el verdadero espíritu de la ley": la posibilidad del aprovechamiento sustentable del bosque. Esta observación, sin embargo, no se condice con el perfil de la institución que nuclea las principales empresas agropecuarias de la zona y que a través de su perfil productivista ha sido históricamente un factor relevante en la expansión territorial del modelo productivo agroindustrial, no solo en el norte cordobés, sino también más allá de sus límites administrativos.

Mediante las asambleas, pero fundamentalmente las consultas públicas, la SRJM se arroga la representación de los territarios 43 
productores ganaderos del norte cordobés, en todos sus estratos. Se debe considerar, en este punto, que es en los predios de los productores familiares donde predominantemente se conservan sectores de monte, o desmontes selectivos en riesgo de comenzar a cerrarse.

Nuevamente, se evidencia la falta de acuerdo existente en torno a la ley, expresada ahora por parte de las mismas entidades que impulsaron el proyecto finalmente aprobado, para quienes las restricciones establecidas son excesivas y representan un avasallamiento a la propiedad privada. De este modo, el enfrentamiento entre los sectores que formaron parte de la COTBN y aquellos representados por las entidades gremiales del campo mantiene su vigencia. Se trata de una puja que, como fue antes señalado, vuelve a tomar la escena con motivo de la propuesta de actualización de la ley impulsada por el gobierno provincial, que amenaza con flexibilizar la normativa vigente.

Un mediano productor ganadero de la zona de Villa María del Río Seco, que reconoció que su único vínculo con la SRJM residía en la vacunación de sus animales (que dicha entidad hegemoniza), sostenía en relación con el OTBN: "[...] los productores que pertenecen a la SRJM necesitan seguir ampliando su área de cultivo $[\ldots] \mathrm{Y}$ como tienen un freno ahí digamos, también empiezan a emigrar a otras provincias donde todavía esos controles no llegaron, como es Santiago del Estero, por ejemplo, que no tienen controles tan estrictos" (productor familiar capitalizado 2, 2013).

El testimonio anterior permite introducir tres elementos de interés en relación con la situación que caracteriza a los departamentos Río Seco, Sobremonte y Tulumba:

i) Cuestionar la representatividad de la SRJM en cuanto a los pequeños productores capitalizados, pudiéndose indicar que en las entrevistas realizadas los de pequeño y mediano estrato no reconocían que la entidad incorporara sus intereses.

ii) Destacar la influencia en los cuestionamientos realizados por la SRJM al OTBN de la necesidad de desmontar para poder "seguir ampliando el área de cultivo".

iii) Reconocer la reglamentación del OTBN como un factor de ralentización del avance de la frontera agraria moderna y problematizar su posible influencia en las transformaciones experimentadas por zonas contiguas, como los departamentos del sur de la provincia de Santiago del Estero.

Finalmente, con respecto al proceso de revisión del OTBN iniciado en 2016, sobre el que aún no hay definición, el anteproyecto impulsado enfrenta la resistencia de organizaciones sociales y de las comunidades campesinas nucleadas en el MCC, observándose la participación de la Ucan en las acciones efectuadas. 
En este orden, en diciembre de 2016 se convocó en la localidad de Villa María del Río Seco (departamento Río Seco), a más de $150 \mathrm{~km}$ de la capital provincial y en el territorio de la SRJM, la audiencia pública obligatoria que viabilizaría la posterior aprobación de la norma. Sin embargo, a horas de realizarse, el poder judicial provincial hizo lugar a un amparo colectivo presentado por las organizaciones para frenarla, aduciendo que violaba el derecho de participación previsto en la Ley de Bosques.

\section{Reflexiones finales}

El artículo estuvo orientado a llevar a cabo una contribución al estudio de las consecuencias ambientales generadas desde fines del siglo XX a través de la expansión territorial del modelo productivo de los agronegocios en Argentina. Específicamente, se centró la atención sobre zonas del centro y norte del país ubicadas en el extremo meridional del Gran Chaco americano. Con esta intención se abordó el proceso de deforestación al que se vieron sometidos los departamentos del norte de la provincia de Córdoba (Río Seco, Sobremonte y Tulumba); se describió la lucha de intereses que puso de manifiesto la sanción de la ley de OTBN provincial; y se analizaron los alcances y perspectivas de la norma con relación a la situación de los bosques nativos locales.

A lo largo del trabajo se buscó articular dos dimensiones íntimamente relacionadas del proceso de transformación que afectó a los bosques nativos del norte cordobés. Por un lado, se caracterizó el proceso concreto de deforestación que afectó el área de estudio, tomando como referencia la periodización definida en trabajos anteriores para temporizar el avance de la frontera agraria moderna sobre los departamentos del norte cordobés. Concretamente, se puso el foco de atención sobre la etapa de agriculturización del norte cordobés que se inicia luego del año 2001, cuando se produce una generalización del cultivo de commodities agrícolas que dinamiza la frontera agraria y se asiste, a su vez, a la aplicación en el territorio provincial de la Ley de Bosques. Por otro, se realizó un recorrido por el proceso de discusión, sanción y reglamentación del OTBN, empleando una estrategia multiescalar que mantuvo la atención sobre los sucesos y sectores sociales situados tanto en la ciudad de Córdoba como en los departamentos bajo estudio. El análisis hecho permitió reconocer, y abordar empíricamente, una de las formas en las que se expresa el encuentro de proyectos antagónicos de ocupación y uso del espacio que da lugar a la formación de la frontera agraria moderna. En esta sintonía, posibilitó superar el mero relevamiento e interpretación de sus efectos materiales directos, para introducir también el debate de sus vínculos con las acciones emprendidas por los distintos sectores sociales que se enfrentan en ella.

Tomando en cuenta el cruce de variables propuesto, el artículo permitió 
reconocer dos tendencias principales en los departamentos del norte cordobés:

i) A nivel de cada uno de ellos, se apreció una distribución heterogénea de las tareas de desmonte, que fue asociada a una hipotética línea de avance de la frontera agraria moderna, cuya orientación predominante está dirigida hacia el norte y este de la provincia. Simultáneamente, luego de la puesta en marcha del OTBN en 2010 se observó una concentración del proceso de deforestación en el sector de montes bajos que comprende el área de transición hacia los pastizales de la depresión de Mar Chiquita (departamentos Río Seco y Tulumba). Esto puede explicarse porque se trata de un sector del área de estudio que fue excluido de los espacios de conservación designados a través de la ley, habilitando así una vía de progresión para el avance de la frontera.

ii) A nivel del conjunto, se evidenció que desde 2003 se produjo un decrecimiento general y continuo del total de hectáreas desforestadas, influido tanto por las trabas impuestas a través del OTBN como por el progresivo agotamiento de los recursos forestales del área correspondiente a la planicie oriental, que representa el sector de mayor interés para la expansión agropecuaria. Esta progresión se revirtió hacia 2016, cuando se inició un radical incremento de los desmontes, en coincidencia con la apertura de la discusión en torno a la actualización del OTBN.

En este sentido, el análisis permitió vincular los picos del proceso de deforestación con momentos concretos del devenir del OTBN, más específicamente con las acciones relacionadas con la conformación de la COTBN para su discusión en 2008; con su sanción y reglamentación entre los años 2010 y 2011 ; y con el inicio del debate en torno a su actualización en 2016.

Volviendo sobre los antagonismos derivados, el trabajo posibilitó indicar la influencia en los departamentos del norte cordobés de las acciones desarrolladas por la SRJM, en tanto representante de las corporaciones agrarias regionales, para buscar una vía de flexibilización del OTBN; así como la participación de la Ucan en las distintas instancias de movilización contra esta tentativa. En ambos casos, se establecieron los vínculos que mantienen estas organizaciones con sus referentes provinciales, dando cuenta así de que la problemática analizada comprende solo la manifestación local de una disputa de mayor alcance que excede incluso al territorio de la provincia.

Finalmente, y a modo de cierre, es importante mencionar que desde el año 2016 se encuentra cumplido el plazo de cinco años que establece la Ley de Bosques para la actualización de los ordenamientos provinciales y desde entonces la situación del oTBN permanece sin definición. Así, 
lejos de tratarse de una problemática ambiental resuelta, la situación de los bosques nativos de la provincia de Córdoba - y más específicamente del norte cordobés- permanece abierta y augura un nuevo período de disputas alrededor de la normativa. De este modo, dos características definen el proceso analizado: la intermitencia de los ciclos de conflictividad social, asociada a los momentos clave del devenir del OTBN; y la evidencia irrefutable de la pérdida de los bosques nativos locales.

\section{Referencias}

Aranda, D. (2015). Tierra arrasada. Petróleo, soja, pasteras y megamineria. Radiografía de la Argentina del siglo $X X I$. Sudamericana.

Benzaquén, L., Blanco, D., Bo, R., Kandus, P., Lingua, G., Minotti, P., \& Quintana, R. (2017). Regiones de bumedales de la Argentina. Ministerio de Ambiente y Desarrollo Sustentable-Fundación Humedales/Wetlands International-Universidad Nacional de San Martín-Universidad de Buenos Aires.

Cabido, M. (2008). Impacto de la agricultura sobre la extensión, distribución y biodiversidad de ecosistemas naturales. En O. Solbrig \& J Adámoli (Coords.), Agro y ambiente: una agenda compartida para el desarrollo sustentable. Foro de la Cadena Agroindustrial Argentina.

Cabido, M., \& Zak, M. (1999). La vegetación del norte de Córdoba. Secretaría de Agricultura, Ganadería y Recursos Renovables de Córdoba.

Cabido, M., \& Zak, M. (22 de junio de 2010). Deforestación, agricultura y biodiversidad. Hoy, La Universidad Digital.

Cartez. (2016). Proyecto de Ordenamiento Territorial de los Bosques Nativos para el arco noroeste de la provincia de Córdoba. "Producir conservando y conservar produciendo". http://www. lavoz.com.ar/sites/default/files/file_attachments/nota_periodistica/ Proyecto_OTBN-_CARTEZ_-_2016. pdf

Coalición TAI Argentina. Ley de Bosques Córdoba. https://sites.google.com/ site/leydebosquescordoba/home

Cotbn. (2009). Proyecto de Ley de Ordenamiento Territorial de Bosques Nativos. Secretaría de Ambiente de la Provincia de Córdoba-Comisión de Ordenamiento Territorial de Bosques Nativos (COTBN).

Cozzo, D. (1992). Las pérdidas del primitivo paisaje de bosques, montes y arbustiformes de la Argentina con especial referencia a sus territorios áridos y húmedos. Academia Nacional de Ciencias-Córdoba, Miscelánea, 90.

Dirección de Bosques. (2017a). Informe de estado de implementación 2010-2016. Ordenamiento Territorial de Bosques Nativos y planes alcanzados por el Fondo Nacional para el Enriquecimiento y la Conservación de los Bosques Nativos. 


\section{tersitarias 43}

Ministro de Ambiente y Desarrollo Sustentable (MAyDS).

Dirección de Bosques. (2017b). Monitoreo de la superficie de bosque nativo de la República Argentina. Año 2016. Unidad de Manejo del Sistema de Evaluación Forestal, Ministro de Ambiente y Desarrollo Sustentable (MAyDS).

FaUba, INTA, \& Redaf. (2019). Proyecto de monitoreo de deforestación en el Chaco Seco. http://monitoreodesmonte.com. ar

Gómez Lende, S., \& Velázquez, G. (2018). Soybean agribusiness in Argentina (1990-2015): socio-economic, territorial, environmental, and political implications. En G. Egilmez (Ed.), Agricultural value chain (pp. 117136). InTech.

Google Earth. (2016). Explore Google Earth. https://earth.google.com/web

Gorenstein, S., \& Ortiz, R. (2016). La tierra en disputa. Agricultura, acumulación y territorio en la Argentina reciente. ReLaER, 1(2), pp. 1-26.

Kopta, F., Cingolani, A., Conti, G., Cáceres, D., Cuchietti, A., Barri, F., Tamburini, D., Torres, R., Martínez, M., \& Enrico, L. (2016). ¿Por qué es necesario mantener la superficie de bosques nativos con categoría I (rojo) en la provincia de Córdoba según el mapa vectorial de la Ley 9814? http://www.lavoz.com.ar/ sites/default/files/file_attachments/ nota_periodistica/Respuesta_OTBN_Cartez_Final.pdf
Kuemmerle, T., Altrichter, M., Baldi, G., Cabido, M., Camino, M., Cuellar, E., ... \& Zak, M. (2017). Forest conservation: remember Gran Chaco. Science, 355(6324), 465-466.

Manuel-Navarrete, D., Gallopín, G., Blanco, M., Díaz-Zorita, M., Ferraro, D., Herzer, H., Laterra, P., Morello, J., Murmis, M., Pengue, W., Piñeiro M., Podesta G., Satorre E., Torrent, M., Torres, F., Viglizzo, E., Caputo, M., \& Celis, A. (2005). Análisis sistémico de la agriculturización en la pampa humeda argentina y sus consecuencias en regiones extra-pampeanas: sostenibilidad, brechas de conocimiento e integración de politicas. Serie Medio Ambiente y Desarrollo $N^{\circ} 118$.

Morello, J., \& Rodríguez, A. (2009). Cómo funcionará el Chaco si se queda sin bosques. En J. Morello \& A. Rodríguez (Eds.), El Chaco sin bosques: la pampa o el desierto del futuro (pp. xi-xviii). Orientación Gráfica Editora.

Morello, J., Rodríguez, A., \& Silva, M. (2009). Clasificación de ambientes en áreas protegidas de las ecorregiones del Chaco Húmedo y Chaco Seco. En J. Morello \& A. Rodríguez (Eds.), El Chaco sin bosques: la pampa o el desierto del futuro (pp. 53-91). Orientación Gráfica Editora.

Redaf. (2019). Red Agroforestal Chaco Argentina - Redaf. http://redaf.org.ar Salizzi, E. (2017). El avance de la frontera agraria moderna sobre el norte cordobés. 
El caso de los departamentos Río Seco, Sobremonte y Tulumba (1990-2015) (Tesis de Doctorado, Facultad de Filosofía y Letras, Área Geografía, UBA). Salizzi, E. (2018a). Los momentos de la frontera agraria moderna en el norte cordobés: la reestructuración productiva de los departamentos Río Seco, Sobremonte y Tulumba. En E. Salizzi \& J. Barada (Comps.), Fronteras en perspectiva/perspectivas sobre las fronteras. Editorial de la Facultad de Filosofía y Letras de la Universidad de Buenos Aires.

Salizzi, E. (2018b). Avance de la frontera agraria moderna y difusión de nuevos sistemas técnicos: la creación y reestructuración de infraestructuras de transporte y almacenamiento de granos en el norte cordobés. Revista Transporte y Territorio, (18).

Salizzi, E. (en prensa). Disputas en torno al uso de agroquímicos en el norte de Córdoba. El caso de Sebastián Elcano. Revista Universitaria de Geografía (RUG).

Saravia Toledo, C., Del Castillo, H., \& Zelarrayan, $H$. (1985). Manejo silvopastoril en el Chaco Noroccidental de Argentina. En IV Reunión de Intercambio Tecnológico en Zonas Áridas y Semiáridas, Salta. Tomo II (pp. 543-556).

Silvetti, F., Soto, G., Cáceres, D., \& Cabrol, D. (2013). ¿’Por qué la legislación no protege los bosques nativos de Argentina? Conflictos socioambientales y políticas públicas. Mundo Agrario, 13(26).

Torrella, S., \& Adámoli, J. (2006). Situación ambiental de la ecorregión del Chaco Seco. En A. Brown, U. Martínez Ortiz, M. Acerbi \& J. Corcuera (Eds.), La situación ambiental argentina 2005 (pp. 75-82). Fundación Vida Silvestre. Totino, M., \& Morello, J. (2013). El Chaco Seco medio siglo antes de la agricultura industrial: procesos de desestructuración de ecosistemas y sociedades rurales. Fronteras, 12, 33-45.

TSCW. (2018). The list of wetlands of international importance. Ramsar: the Secretariat of the Convention on Wetlands.

Vera, A. (2015). El primer ordenamiento territorial de bosques nativos de Córdoba: algunos aspectos políticos e institucionales del proceso participativo. En M. L. Foradori (Coord.), La investigación jurídica en politicas públicas ambientales. Parte II (pp. 211-231). Universidad Nacional de Córdoba.

Vera, A. (2017). Aportes legales para la actualización del ordenamiento territorial de bosques nativos de Córdoba. Red Educativa para el Acceso a la Información Pública Ambiental. https://www.accesoambiental.net.ar/ single-post/2017/06/23/Aportes-legales-para-la-actualizaci $\% \mathrm{C} 3 \% \mathrm{~B} 3 \mathrm{n}$-delordenamiento-territorial-de-bosquesnativos-de-C\%C3\%B3rdoba territarios 43 27 
Zarrilli, A. (2000). Transformación ecológica y precariedad económica en una economía marginal: el Gran Chaco argentino, 1890-1950. Theomai: Estudios sobre Sociedad, Naturaleza y Desarrollo, 1.

\section{Entrevistas}

Pequeño productor familiar l. Cercanías del paraje Encrucijadas, Río Seco. Mayo de 2015 .
Productor familiar capitalizado 1. Paraje Victoria Este, Río Seco. Mayo de 2015. Productor familiar capitalizado 2. Villa de María del Río Seco, Río Seco. Agosto de 2013.

Representante de la AER INTA Jesús María. Jesús María, Colón. Mayo de 2015.

Representante de la SRJM en Villa de María del Río Seco. Jesús María, Colón. Mayo de 2015.

Representante del MAyG. Villa de María del Río Seco, Río Seco. Mayo de 2015. 